\title{
Use of Techniques for Scleral and Iris Fixation in Secondary Implantation of Intraocular Lenses
}

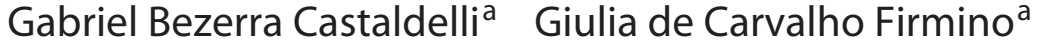 \\ Volney Anderson Castaldelli ${ }^{b}$ Rafael de Souza $\operatorname{Costa}^{b}$ João Crispim Ribeiro ${ }^{a, b}$ \\ ${ }^{a}$ Department of Ophthalmology, Christus University Center (Unichristus), Fortaleza, Brazil; b Department of \\ Ophthalmology, Instituto Cearense de Oftalmologia (ICO), Fortaleza, Brazil
}

\section{Keywords}

Cataract surgery · Aphakia · Intraocular lens implantation · Iris - Sclera

\begin{abstract}
Scleral and iris fixation of intraocular lenses (IOL) are useful in the treatment of surgical or traumatic aphakia, luxation, and subluxation of $\mathrm{IOL}$ if the patient does not present appropriate capsular support. However, there is no consensus in the literature about which of these 2 methods is safer and better. The authors performed a literature review searching the main postoperative outcomes obtained with the use of each surgical method. Scleral and iris fixation of IOL are efficient in correction of the patients' visual acuity, even though each technique presents distinct complications which depend especially on the experience of the surgeon with the performed surgical method. It is important to understand that individuals submitted to scleral or iris fixation present previous preoperative complications in their eyes. Besides, both procedures are very complex, involving intense manipulation of the eye globe. The success rate of these surgical techniques is highly variable and has a close relation to the preoperative conditions of the patient's eye and the improvement of the surgeon's learning curve.
\end{abstract}

(c) 2020 S. Karger AG, Basel
(C) 2020 S. Karger AG, Basel

www.karger.com/ore

Karger"

\section{Introduction}

The most appropriate location to implant intraocular lenses (IOL) is the interior of the capsular bag, but complicated cataract surgeries and procedures of secondary IOL implantation are associated with insufficiency or absence of stability from this anatomic structure. In these cases, the IOL must be fixated at alternative sites of the eye globe, e.g., in the iris or the sclera $[1,2]$.

The main surgical indications for secondary implantation of IOL are surgical or traumatic aphakia and the complications associated with primarily implanted IOL, such as traumatic luxation or subluxation, opacification, and uveitis-glaucoma-hyphema syndrome, which is usually associated with the use of IOL in the anterior chamber (Table 1). Displacement of the IOL is the main reason for secondary implants, justifying $75 \%$ of these types of procedures, followed by surgical aphakia and lens opacification, which correspond to 19 and $6 \%$ of the cases of secondary IOL implantation, respectively [3].

Data from the American College of Ophthalmology (ACO) demonstrate that sutured scleral fixation and sutured iris fixation, in the posterior chamber, are safe and effective techniques for the correction of surgical aphakia, luxation, and subluxation of IOL when the capsular support is absent. However, the ACO does not provide

Gabriel Bezerra Castaldell

Department of Ophthalmology, Christus University Center (Unichristus) Rua João Adolfo Gurgel 133

Fortaleza, Ceará 60190-060 (Brazil)

gabrielcastaldelli@hotmail.com 
Fig. 1. Flow chart of the literature review.

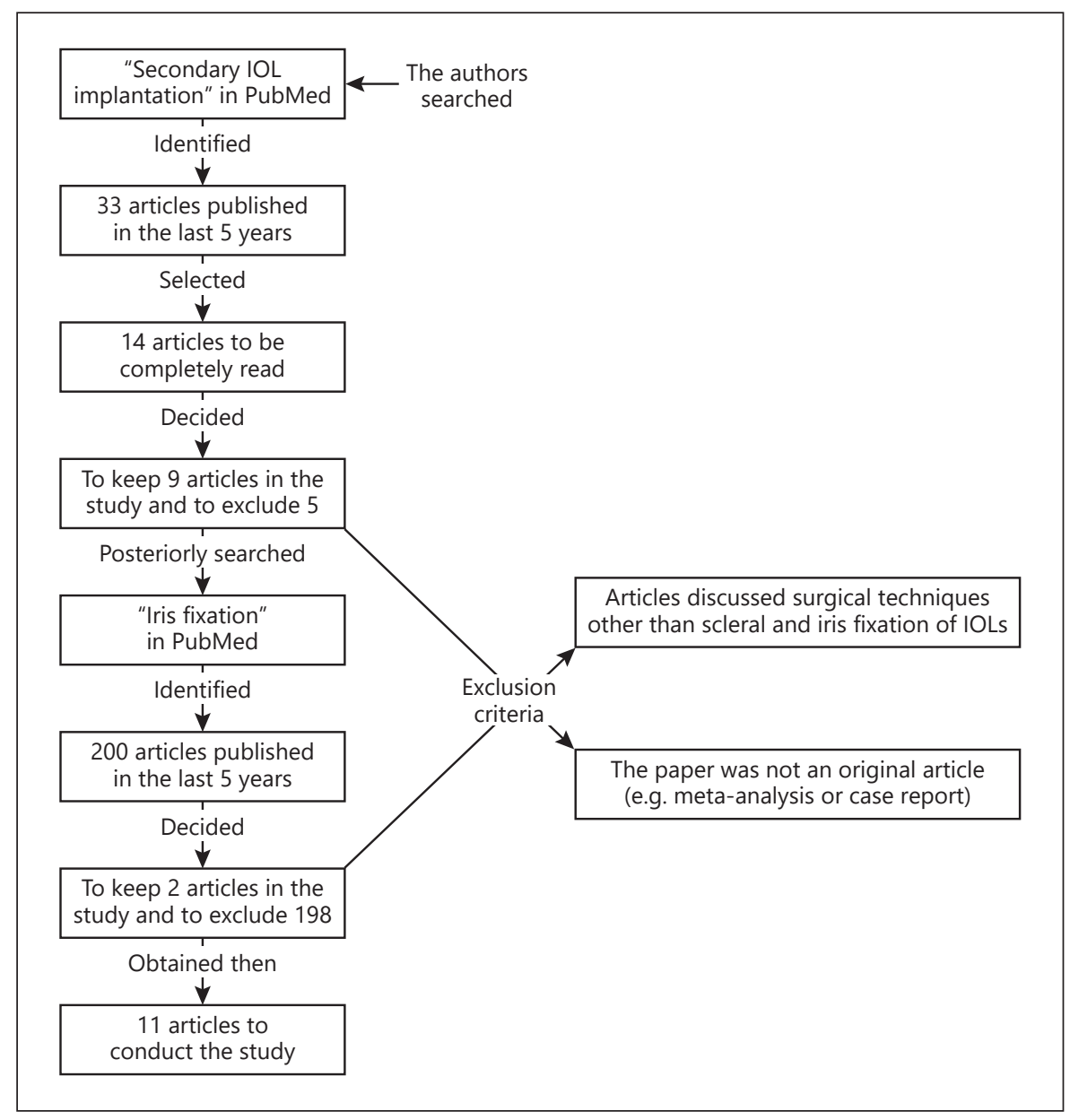

Table 1. Main etiologies for the secondary implantation of IOL

- Complicated cataract surgery without capsular preservation

- Surgical or traumatic aphakia

- Traumatic luxation

- Opacification of the IOL

- Uveitis-glaucoma-hyphema syndrome

enough evidence to determine the superiority of one technique over the other. This reflects the lack of a consensus in the literature concerning which method is safer and better [4].

The purpose of this study is to evaluate, through a literature review, the clinical outcomes of iris fixation and scleral fixation in the context of secondary IOL implantation. The authors present the most relevant technical aspects of these surgical procedures and the main postoperative outcomes obtained with the use of each of these methods.

\section{Methods}

The authors conducted a systematic review at PubMed concerning the use of scleral and iris fixation on the secondary implantation of IOL. Initially, a combination of the terms secondary IOL implantation was used to identify eligible articles for this study (Table 2).

The research on the database identified 33 potentially relevant articles and 14 of them were selected to be thoroughly analyzed. Among these 14 articles, the authors decided to keep 9 of them in the literature review, while the other 5 were excluded from the study for the following reasons: 3 of them addressed secondary IOL implantation techniques other than scleral and iris fixation, 1 of them was a meta-analysis, and the last one was a case report.

The inclusion criteria were: $<5$ years since publication and evaluation of the use of scleral or iris fixation on secondary IOL implantation. The exclusion criteria were: not being an original article or addressing of surgical methods of secondary IOL implantation other than scleral and iris fixation.

Posteriorly, to include more articles about iris fixation of IOL in the study, the authors searched for the terms iris fixation in PubMed. This research identified 200 articles about the subject, published throughout the last 5 years. Among these 200 articles, 2 
Table 2. Description of studies included on the literature review

\begin{tabular}{|c|c|c|}
\hline Study & Type of study & Description \\
\hline Chantarasorn et al. [38] & Retrospective & $\begin{array}{l}\text { Double-sutured scleral vs. intrascleral } \\
\text { fixation }\end{array}$ \\
\hline Faria et al. [17] & Retrospective & $\begin{array}{l}\text { Iris fixation of subluxated or luxated 3-piece } \\
\text { IOL }\end{array}$ \\
\hline Faria et al. $[34]$ & Retrospective & Iris claw fixation \\
\hline Hernández Martínez and González [35] & Retrospective & Iris claw fixation in patients with aphakia \\
\hline McKee et al. [42] & Retrospective & Fibrin glue assisted intrascleral fixation \\
\hline Mizuno and Sugimoto [39] & Retrospective & Transscleral vs. sutureless scleral fixation \\
\hline Nehme et al. [28] & Retrospective & Transscleral vs. iris fixation \\
\hline Oh et al. [46] & Retrospective & Fibrin glue-assisted sutureless scleral fixation \\
\hline Sindal et al. [43] & Retrospective & Sutured vs. sutureless scleral fixation \\
\hline Touriño Peralba et al. [9] & Retrospective & Prepupillary vs. retropupillary iris fixation \\
\hline Zhang et al. [13] & Prospective & Scleral vs. iris fixation \\
\hline
\end{tabular}

of them were selected for integration into this study based on the inclusion and exclusion criteria previously mentioned.

Therefore, the authors gathered 11 articles for the development of this literature review - 5 of them addressing scleral fixation, 4 of them focusing on iris fixation, and the other 2 comparing both techniques. Every article from the study was chosen until December 1, 2018 (Fig. 1).

\section{Results}

\section{Surgical Technique}

Iris Fixation

Iris fixation is a corrective technique for surgical aphakia that is considered to be easier to perform for the anterior segment surgeon. To implement this procedure, the patient must present the following factors: iris integrity, depth of the anterior chamber $\geq 3 \mathrm{~mm}$, and, preferably, an endothelial cell count $\geq 1,200$ cells $/ \mathrm{mm}^{2}$ [5-9].

The contraindications for iris fixation include: pigmented neovascular or advanced glaucoma, pseudoexfoliation syndrome, a very low endothelial cell count $\left(<1,000\right.$ cells $\left./ \mathrm{mm}^{2}\right)$, a shallow anterior chamber $(<3 \mathrm{~mm}$ of depth), serious iris trauma, and iridodialysis or atrophy of the iris [6, 10-13].

Iris fixation uses peribulbar or topic anesthesia. The operation begins with a corneal incision or a scleral tunnel, prepared $2 \mathrm{~mm}$ away from the limbus. After the incision, the surgeon utilizes a Shepard clamp to position the iris claw IOL, which may be placed at a prepupillary or retropupillary site $[6,14]$. After this, the haptics are fixated to the iris with a reverse Sinskey hook or with a 27 -gauge needle bent to 45 degrees. The haptics must go through the paracentesis, at 3 and 9 o'clock, to apprehend

Techniques for Scleral and Iris Fixation of IOL a sufficient portion of iris tissue. The visualization of the iris dimples suggests that the IOL interlocking is correct. When the IOL is at a retropupillary site, the surgeon pushes one haptic after the other to the posterior region of the iris. During this maneuver, the Shepard clamp holds the optic section of the IOL, preventing its displacement. Finally, a $10-0$ Nylon ${ }^{\circledR}$ needle closes the corneal wound and the surgeon might remove the suture points after 8 weeks, depending on the refractive and topographic astigmatism of the patient $[15,16]$.

If the patient has no aphakia but presents a posteriorly subluxated or luxated 3-piece IOL, the surgical approach must be done through the posterior segment of the eye. The operation begins with peribulbar anesthesia and proceeds to a sclerotomy and a pars plana vitrectomy to release the vitreous in the anterior chamber and around the IOL. After removal of the capsular debris, the surgeon applies a viscoelastic solution, to protect the corneal endothelium, and perfluorocarbon to protect the macula, thus ensuring easy and safe manipulation of the IOL [17-19].

Following these procedures, placement of the IOL in the anterior chamber occurs, keeping the eyes posterior to the iris. After this, the surgeon must inject acetylcholine $\left(\right.$ Miochol ${ }^{\circledR}$ ) into the eye globe, causing an optical capture of the central piece of the IOL, which allows fixation of the haptics to the iris with a $10-0$ Prolene ${ }^{\circledR}$ needle. A 23-gauge clamp is used to tie the sutures with 3 knots. The surgeon repeats the same procedure on the second haptic, fixating the IOL in 2 different points. When the haptics is held, the optic section of the IOL is smoothly pushed posteriorly. The procedure ends with removal of the viscoelastic solution and careful evaluation of the integrity of the retina's periphery [17-19]. 
Fig. 2. Scleral sutured fixation of IOL in a 68-year-old female patient with IOL subluxation. a Pre-operative eye. b Marks to determine the place of the sclerotomies. c Insertion of sclerotomy. d Performance of the posterior vitrectomy. e Insertion of the suture needle into the eye globe. $f$ Externalization of the suture wire with a forceps.
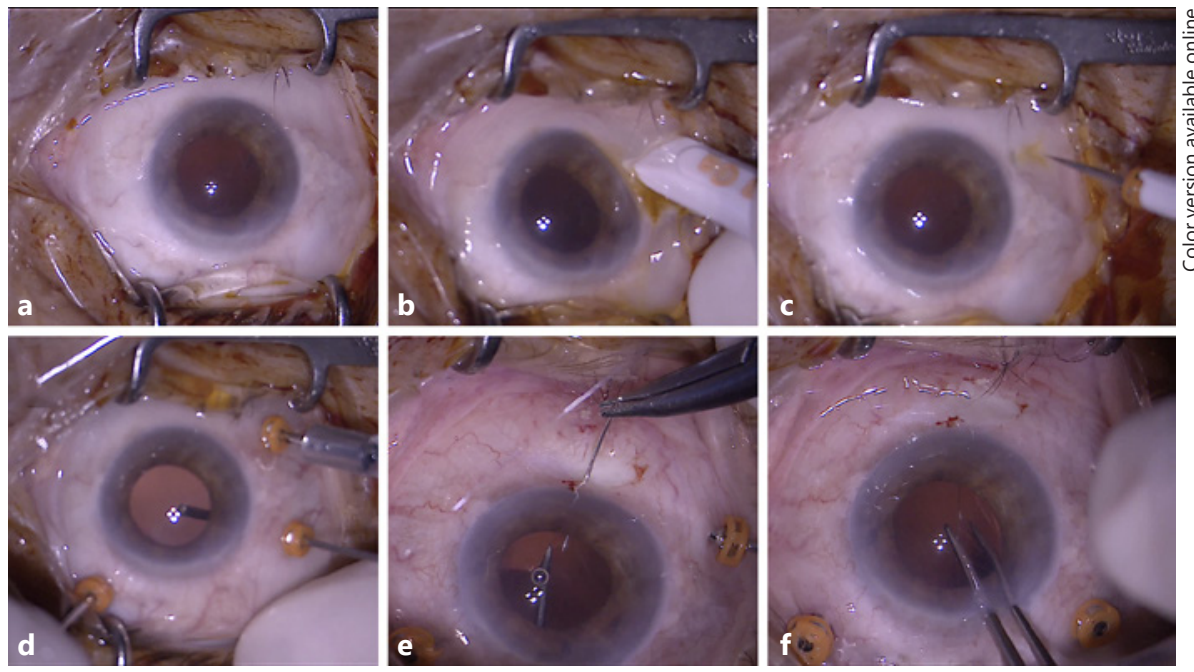

\section{Scleral Fixation}

Scleral fixation is another strategy to correct a cataract, surgical aphakia, or luxation or subluxation of IOL or the lens. The method relies mostly on an experienced posterior chamber surgeon and presents a greater intraoperative risk in comparison with iris fixation [20]. The scleral technique has 2 different subtypes: sutured and sutureless fixation. In the sutureless variation of the procedure, the haptics are fixated in tunnels, which may be reinforced with fibrin glue [21-23]. It is also important to mention the flanged technique, in which the extremity of the haptic is cauterized to acquire a larger diameter. This method gives better support of the suture wires to the haptic. Moreover, it allows enhanced attachment of the haptic to the sclera in the sutureless technique [24, 25].

Scleral fixation might be indicated even if the eye presents a low endothelial cell count $(<1,000-1,200$ cells/ $\left.\mathrm{mm}^{2}\right)$, a shallow anterior chamber $(<3 \mathrm{~mm}$ of depth), glaucoma, or anatomical distortion of the iris, factors that would contraindicate iris fixation [26, 27]. Nevertheless, the scleral technique cannot be performed in patients with recurrent uveitis, a serious iris injury, corneal edema, uncontrolled glaucoma, proliferative diabetic retinopathy, or macular lesions [28].

Scleral fixation uses peribulbar anesthesia. It begins with infusion of a balanced solution into the eye globe, followed by sclerotomy and posterior vitrectomy, preferably with a 25-gauge device, to improve postoperative results. After that, the surgeon performs a corneoscleral incision of 3.5 or $5.5 \mathrm{~mm}$, at the 11 -h position, which allows removal of a subluxated IOL. Then the surgeon might create squared scleral flaps at the 3 and 9-h positions, put- ting their bases on the limbus and reaching, on average, one third of the scleral depth.

In the sutured technique, a straight 10-0 polypropylene suture wire is attached to the IOL haptic, and then a forceps is used to externalize it through the scleral flap and, finally, the haptic is sutured to the sclera. The same maneuver is repeated on the second scleral flap to fixate the IOL $[22,29]$.

In the sutureless technique, one of the haptics is kept outside the anterior chamber, after injection of the IOL, which prevents it from falling into the vitreous cavity. At that point, the surgical technique may vary. Some surgeons construct scleral tunnels to fixate the haptics with or without the assistance of fibrin glue. Other surgeons prefer to make a scleral paracentesis to expose the haptics, cauterizing or attaching them to the sclera with fibrin glue and finishing the procedure by covering the paracentesis [30-33].

The scleral fixation technique is highly variable. For example, the scleral flaps, which may allow easier externalization of the suture wires, can sometimes not be performed. Figures 2 and 3 illustrate a variation of sutured scleral fixation without the creation of scleral flaps. In this procedure, the suture wires are externalized through the limbus.

\section{Clinical Outcomes}

\section{Iris Fixation}

Iris fixation presents safe and efficient results in the improvement of postoperative visual acuity. Evaluation of the safety profile of this technique must consider the fact that patients treated with this type of surgery com- 
Fig. 3. Same patient and the same procedure as in Figure 2. a Injection of the IOL. b Attachment of the suture wire to the IOL haptic. c, d Scleral suture in the inferior and superior poles of the eye globe, respectively. e Adjustment of the IOL position. f Postoperative eye.
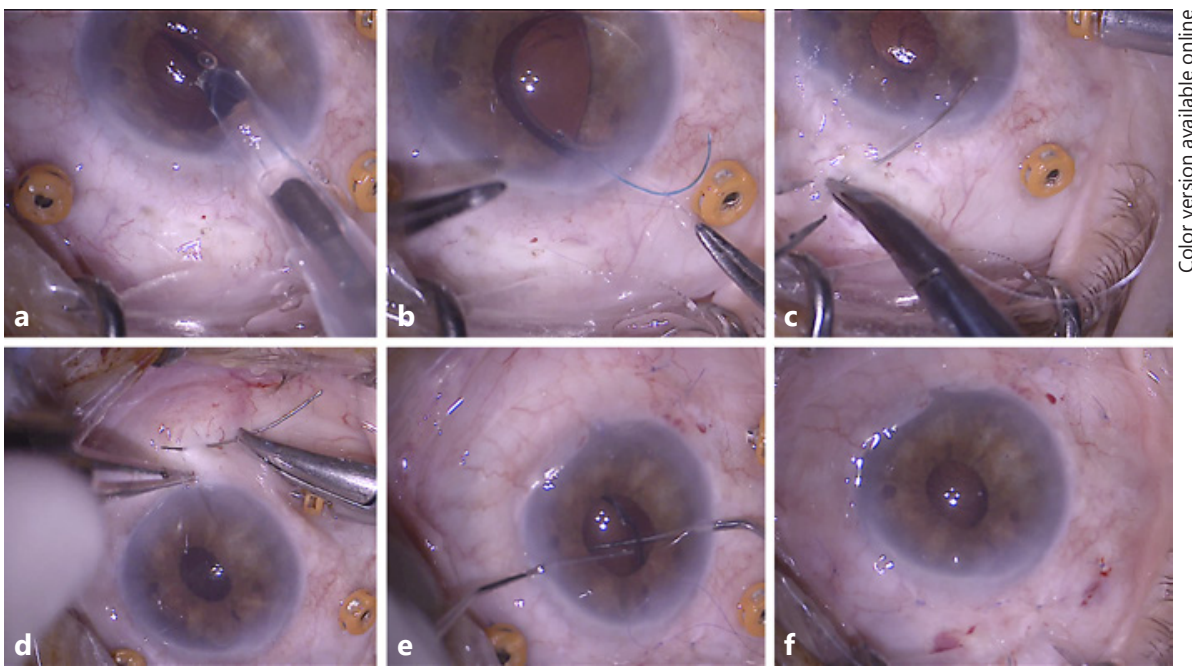

monly have preoperative complications, such as surgical aphakia, luxation, or subluxation of IOL [34].

Faria et al. [34] identified a mean visual improvement of $0.909 \log$ MAR units in 66 eyes submitted to pars plana vitrectomy and retropupillary implantation of one-piece iris claw IOL. Faria et al. [17], evaluated the visual acuity improvement of 36 eyes submitted to prepupillary implantation of 3-piece IOL, which were sutured to the iris. In that case, there was a mean increase of 4.08 lines $( \pm 5.33)$ in the logMAR scale [17].

Comparisons of prepupillary versus retropupillary iris implantation of IOL reveal that both of them are efficient in the correction of surgical aphakia. However, the literature suggests that more complications affect patients that realize prepupillary iris implantation. The loss of endothelial cells, which is associated with a higher risk of corneal decompensation, as well as cystoid macular edema, occurs more frequently with the prepupillary technique, even though the literature lacks statistically significant data to confirm this tendency $[9,35]$.

Iris fixation may use 2 different types of incision - corneal cut or scleral tunnel. Each variant of incision is related to a different prevalence of postoperative complications, especially because greater corneal manipulation may induce the development of astigmatism. Hernández Martínez and González [35] identified that the mean secondary astigmatism in patients submitted to iris fixation of IOL was significantly lower in the scleral tunnelization group versus the corneal incision group $(0.73 \pm 0.62$ vs. $2.49 \pm 1.36$; $p<0.001$ ).

Finally, it is important to highlight the fact that pupillary distortion or ovalization is a common postoperative consequence of iris implantation of IOL. This might happen in $4.2-32 \%$ of patients submitted to this type of procedure, leaving them with potentially uncomfortable or embarrassing esthetical stigmas. Patients must be thoroughly alerted about the possibility of these ocular deformities [9].

\section{Scleral Fixation}

The scleral fixation technique is also a safe and efficient alternative for visual correction of aphakic patients without posterior capsular support. Originally, this surgical method required the use of suture knots. However, Gabor and Pavlidis [22] reported a pioneering technique of sutureless intrascleral fixation through fixation of the haptics into scleral tunnels. The majority of studies have demonstrated that there are no statistically significant differences in visual acuity improvement in patients submitted to sutured or sutureless scleral fixation. Nevertheless, postoperative complications are usually more severe in sutured scleral implantation, particularly related to the breakage of suture wires and ocular hypotony.

Price et al. [36] described rupture of the wires in the sutured scleral technique 7-14 years after the operation. The same paper suggests that the use of thicker wires would guarantee a better durability of the suture's integrity, particularly with replacement of $10-0$ to $9-0$. The Gore-Tex suture wire is another alternative tool for sturdier scleral fixations and might be a good replacement for Prolene. Gore-Tex consists of a polytetrafluoroethylene monofilament, a nonabsorbable suture, originally used in cardiovascular procedures. Khan et al. [37] did not identify any suture breakage after evaluating 85 eyes 
submitted to sutured scleral fixation with Gore-Tex, throughout a mean follow-up of 325 days. However, the literature still lacks studies with longer follow-up periods to guarantee that Gore-Tex is truly stronger than Prolene.

Chantarasorn et al. [38] evaluated 26 eyes of a group of patients submitted to double-sutured scleral fixation and compared them to another 22 eyes submitted to sutureless intrascleral fixation; flexible 3-piece IOL were used in both groups. The authors compared 2 different parameters of the double-sutured scleral fixation group versus intrascleral fixation group: the postoperative stability of IOL ( $2.90 \pm 0.77$ vs. $2.82 \pm 0.72 ; p=0.633)$ and decentration of IOL $(151.90 \pm 59.80$ vs. $175.00 \mu \mathrm{m} \pm$ 73.14; $p=0.265$ ). The results from the 2 groups had no statistically significant differences and the visual acuity of patients improved similarly with both surgical techniques. In the 12-month follow-up, only 3 eyes from the intrascleral fixation group (13.6\%) developed ocular hypotony. There were no other complications reported in the study.

Mizuno and Sugimoto [39] also compared sutured and sutureless scleral fixation. In their paper, 45 eyes were submitted to sutured transscleral fixation and another 44 eyes to sutureless scleral fixation; flexible 3-piece IOL were used in both groups. There was visual acuity improvement with both techniques, without statistically significant differences between them. The degree of induced astigmatism, in dioptries, was significantly lower in the sutureless group after 1 week $(1.58 \pm 1.33$ vs. $2.51 \pm 1.48$; $p=0.0046)$ and 1 month (1.47 \pm 1.45 vs. $2.30 \pm 1.31 ; p=$ $0.021)$.

The study of Mizuno and Sugimoto [39] suggests that sutureless implantation of IOL in scleral tunnels offers greater support and stability to the IOL than the sutured transscleral technique. For this reason, there were lower rates of postoperative secondary astigmatism in the sutureless intrascleral fixation group [39]. After all, larger degrees of IOL tilt or decentration are associated with a greater incidence of induced astigmatism [40,41]. Nevertheless, this better stability of sutureless intrascleral IOL contrasts with the data of Chantarasorn et al. [38], which affirms that there is no difference in stability between the 2 scleral fixation techniques.

Mizuno and Sugimoto [39] also identified that the 45 eyes from the sutured transscleral fixation group had a greater incidence of complications, including ocular hypotension (18.1\%) or hypertension (9.1\%), vitreous hemorrhage $(9.1 \%)$, IOL tilt (8.9\%), vitreous incarceration $(2,2 \%)$ and iris capture (2.2\%). While the complications in the 44 eyes of the sutureless intrascleral fixation group included ocular hypertension (9.1\%), iris capture (6.9\%), IOL tilt (4.5\%), vitreous hemorrhage (2.5\%), and a single case of corneal ulceration (2.3\%).

It is important to highlight that ocular hypotension was the most common complication of the sutured transscleral fixation group and happened exclusively with this technique [39], this fact contrasts once again with the results of Chantarasorn et al. [38], in which ocular hypotony only developed in patients submitted to sutureless intrascleral fixation.

The variation of results in the literature may be justified by the very recent introduction of scleral tunnelization as an alternative surgical method, in association with the fact that the surgeon's learning curve directly interferes with the prevention of postoperative complications. In other words, the experience of these professionals is a determinant factor in the reduction of complication incidence. Thus, greater affinity and skill of the cataract surgeon with sutured or sutureless scleral fixation favor one technique or the other [42].

Sindal et al. [43] also compared sutured versus sutureless scleral fixation. They evaluated 50 eyes submitted to sutured scleral fixation and 59 eyes to sutureless scleral fixation, keeping a mean follow-up time of 18.9 months $( \pm 8.7)$. There was improvement in visual acuity in both groups, without statistically significant differences between them.

The most common complications, in both groups, was transitory cystoid macular edema in 13 eyes (12\%), followed by retinal detachment in 5 eyes (4.5\%). There were also 3 single postoperative occurrences: 1 full-thickness macular hole on the 15th month of follow-up, 1 eye with decompensated glaucoma, and a suture rupture with IOL detachment, which was corrected without intercurrences. The 2 groups had the same proportion of complications and the 2 surgical techniques were considered equally effective in the correction of surgical or traumatic aphakia [43].

Regarding sutureless scleral fixation, it is possible to alternatively perform it with fibrin glue, a technique originally described by Agarwal et al. [44] and posteriorly improved as the handshake technique [45]. This update consists of manipulation of the 2 IOL haptics, simultaneously, with a pair of forceps, which guarantees a simpler and safer externalization of these structures. McKee et al. [42] evaluated the outcomes obtained with the handshake technique in 50 eyes, achieving a mean increase in visual acuity from $20 / 200$ in the preoperative setting to $20 / 50$ after the surgery.
Ophthalmic Res 2021;64:1-9
DOI: $10.1159 / 000507120$
Castaldelli/Firmino/Castaldelli/Costa/ Ribeiro 
Among the postoperative complications reported in the 50 eyes, ocular hypotony occurred in 11 of them (22\%) - 10 of those eyes had a spontaneous recovery, but 1 of the eyes needed surgical sealing of a leakage from the scleral tunnel. Further complications involved 3 individual cases of vitreous hemorrhage, cystoid macular edema, and 1 case of traumatic rupture of the IOL optic zone from its haptic, which was corrected without intercurrences [42].

McKee et al. [42] reported that insertion of the haptic is the most challenging part of this new method of scleral IOL fixation with fibrin glue. In order to optimize the operation and overcome any technical difficulties, the authors made 2 modifications to the original method: first they exchanged the hard polymethacrylate or polypropylene IOL for more flexible and less breakable lenses, then they started lifting only 2 margins from the scleral flaps, creating a more stable and symmetrical tunnel to sustain the haptics into the sclera.

Oh et al. [46] also evaluated the use of fibrin glue in 25 eyes submitted to sutureless scleral fixation. These patients had previously undergone cataract surgeries and presented luxated IOL into the posterior segment of the eye. The authors compared a group of 13 eyes in which the IOL were reused (reimplantation group) versus 12 other eyes that used new IOL (replacement group).

There was an improvement in visual acuity, in spherical equivalents, when comparing the preoperative period versus the 6-month follow-up both in the reimplantation group (5.98 \pm 4.42 vs. $-0.84 \pm 1.75 ; p=0.005)$ and in the replacement group $(4.29 \pm 2.85$ vs. $-1.35 \pm 1.37 ; p=$ 0.003 ), without statistically significant differences between them. There was also enhancement of the induced corneal astigmatism, in spherical equivalents, 1 versus 6 months after the operation both in the reimplantation group ( $0.90 \pm 0.47$ vs. $0.61 \pm 0.37 ; p=0.012)$ and in the replacement group $(1.17 \pm 0.64$ vs. $0.73 \pm 0.37 ; p=0.037)$, also without statistically significant differences between them [46].

In the reimplantation group, 4 eyes had postoperative complications, including individual cases of optic capture of the IOL, serous central chorioretinopathy, retinal detachment, and ocular hypertension. In the replacement group, 3 eyes presented complications involving single cases of cystoid macular edema, vitreous incarceration, and IOL decentration. Despite this, IOL refixation or substitution are both safe and efficient measures that might be performed in the sutureless scleral fixation of IOL with fibrin glue [46].

Techniques for Scleral and Iris Fixation of IOL

\section{Comparison of the Two Techniques}

Nehme et al. [28] compared the performance of posterior chamber IOL implanted with sutured transscleral technique versus the iris fixation technique. In total, 28 eyes were included in this study; 13 of them were submitted to transscleral fixation and the other 15 eyes received iris fixation. In a 3-year follow-up, the 2 groups presented an important improvement of visual acuity, without statistically significant differences between them.

The group of transscleral fixation had 7 eyes with postoperative complications: a vitreous hemorrhage, secondary glaucoma, a cystoid macular edema, an IOL tilt, a retinal detachment, and 2 cases of keratitis. The group of iris fixation had 5 eyes with postoperative complications: keratitis, secondary glaucoma, a cystoid macular edema, a hyphema, and a retinal detachment. There were no statistically significant differences in postoperative complication rates between the 2 groups [28].

Zhang et al. [13] also compared iris fixation versus sutured scleral fixation in a prospective and randomized trial. Altogether, 63 eyes were included in this study; 31 were submitted to iris fixation and 32 to scleral fixation. The preoperative data were compared with the results obtained after a 3-month follow-up period. The iris fixation group had more eyes with visual improvement than the group of scleral fixation, i.e., $12(38.71 \%)$ versus 4 eyes $(12.5 \%)(p=0.017)$. Worsening of visual acuity was more frequent in the scleral fixation group than in the iris fixation group, i.e., 18 (56.25\%) versus 9 eyes (29.03\%) ( $p=$ 0.029 ).

In the trial, there were more complications related to scleral fixation. Overall, this group presented 18 complicated eyes: 5 cases of intraoperative hyphema, 2 vitreous hemorrhages, 6 IOL tilts, 1 secondary glaucoma, and 4 exposed suture knots. The iris fixation group presented 7 complicated eyes: 4 cases of intraoperative hyphema, 2 vitreous hemorrhages, and 1 case of secondary glaucoma [13].

Zhang et al. [13] considered the iris fixation method safer and more efficient than the scleral fixation, as there were better visual acuity outcomes and lower incidence of postoperative complications. This contrasts with the results obtained by Nehme et al. [28], who concluded that both methods of secondary IOL implantation were equivalent. These divergences demonstrate the need for more trials aiming to obtain a consensus concerning the efficiency and the safety of both of these techniques. 


\section{Conclusion}

The authors conclude that both scleral and iris fixation of IOL are efficient and safe techniques for the treatment of surgical aphakia, luxation, and subluxation of IOL in patients with inadequate capsular support. In general, the literature considers both methods to be equivalent, even though a few papers suggest that one technique might be superior to the other. However, comparative trials of these 2 types of surgery are still scarce and need to be better studied. Finally, it is important to highlight the fact that scleral and iris fixation is performed in eyes with previous complications despite the fact that both methods involve intense manipulation of the ocular globe. Therefore, their rate of success is highly variable and very dependent on the surgeon's learning curve.

\section{References}

1 Brunin G, Sajjad A, Kim EJ, Montes de Oca I, Weikert MP, Wang L, et al. Secondary intraocular lens implantation: complication rates, visual acuity, and refractive outcomes. J Cataract Refract Surg. 2017 Mar;43(3):369-76.

2 Kumar S, Singh S, Singh G, Rajwade NS, Bhalerao SA, Singh V. Visual outcome and complications of various techniques of secondary intraocular lens. Oman J Ophthalmol. 2017 Sep-Dec;10(3):198-204.

3 Vounotrypidis E, Schuster I, Mackert MJ, Kook D, Priglinger S, Wolf A. Secondary intraocular lens implantation: a large retrospective analysis. Graefes Arch Clin Exp Ophthalmol. 2019 Jan;257(1):125-34.

4 Wagoner MD, Cox TA, Ariyasu RG, Jacobs DS, Karp CL; American Academy of Ophthalmology. Intraocular lens implantation in the absence of capsular support: a report by the American Academy of Ophthalmology. Ophthalmology. 2003 Apr;110(4):840-59.

5 Chen Y, Liu Q, Xue C, Huang Z, Chen Y. Three-year follow-up of secondary anterior iris fixation of an aphakic intraocular lens to correct aphakia. J Cataract Refract Surg. 2012 Sep;38(9):1595-601.

6 Güell JL, Verdaguer P, Elies D, Gris O, Manero F, Mateu-Figueras G, et al. Secondary irisclaw anterior chamber lens implantation in patients with aphakia without capsular support. Br J Ophthalmol. 2014 May;98(5):65863.

7 De Silva SR, Arun K, Anandan M, Glover N, Patel CK, Rosen P. Iris-claw intraocular lenses to correct aphakia in the absence of capsule support. J Cataract Refract Surg. 2011 Sep; 37(9):1667-72.

\section{Acknowledgement}

The authors received structural support from Centro de Laser e Diagnose Ocular (CLDO) in obtaining the images of this paper.

\section{Disclosure Statement}

The authors have no conflict of interests to declare.

\section{Funding Sources}

The authors have no funding sources to declare.

\section{Author Contributions}

G.B.C. wrote the original draft of the Abstact, the Introduction, and the main text, made the final corrections in the text and elaborated the images and tables. G.C.F. wrote the original draft of the Methods and the main text. V.A.C. wrote the original draft of the main text. R.S.C. reviewed all of the content in this paper. J.C.R. planned, led, and reviewed all of the content in this paper.
8 Sawada T, Kimura W, Kimura T, Suga $H$, Ohte A, Yamanishi S, et al. Long-term followup of primary anterior chamber intraocular lens implantation. J Cataract Refract Surg. 1998 Nov;24(11):1515-20.

9 Touriño Peralba R, Lamas-Francis D, Sarandeses-Diez T, Martínez-Pérez L, Rodríguez-Ares T. Iris-claw intraocular lens for aphakia: can location influence the final outcomes? J Cataract Refract Surg. 2018 Jul; 44(7):818-26.

10 Haripriya A, Sharma SS. Retro iris suture fixation of a rigid intraocular lens. J Cataract Refract Surg. 2016 Nov;42(11):1556-61.

11 Yazdani-Abyaneh A, Djalilian AR, Fard MA. Iris fixation of posterior chamber intraocular lenses. J Cataract Refract Surg. 2016 Dec; 42(12):1707-12.

12 Lyle WA, Jin JC. Secondary intraocular lens implantation: anterior chamber vs posterior chamber lenses. Ophthalmic Surg. 1993 Jun; 24(6):375-81.

13 Zhang H, Zhao J, Zhang LJ, Liu J, Liu Y, Song $\mathrm{W}$, et al. Comparison of iris-fixated foldable lens and scleral-fixated foldable lens implantation in eyes with insufficient capsular support. Int J Ophthalmol. 2016 Nov;9(11): 1608-13.

14 Forlini M, Soliman W, Bratu A, Rossini P, Cavallini GM, Forlini C. Long-term follow-up of retropupillary iris-claw intraocular lens implantation: a retrospective analysis. BMC Ophthalmol. 2015 Oct;15(1):143.

15 Baykara M, Ozcetin H, Yilmaz S, Timuçin OB. Posterior iris fixation of the iris-claw intraocular lens implantation through a scleral tunnel incision. Am J Ophthalmol. 2007 Oct; 144(4):586-91.
16 Kwon HJ, Nam SM, Stulting RD, Lim CY, Seo $\mathrm{KY}$. Comparison of surgically induced astigmatism following iris-claw PIOL insertion with scleral, limbal, or corneal incisions. J Refract Surg. 2014 May;30(5):330-5.

17 Faria MY, Ferreira NP, Canastro M. Management of dislocated intraocular lenses with iris suture. Eur J Ophthalmol. 2017 Jan;27(1): 45-8.

18 Garcia-Rojas L, Paulin-Huerta JM, ChavezMondragon E, Ramirez-Miranda A. Intraocular lens iris fixation. Clinical and macular OCT outcomes. BMC Res Notes. 2012 Oct; 5(1):560

19 Condon GP, Masket S, Kranemann C, Crandall AS, Ahmed II. Small-incision iris fixation of foldable intraocular lenses in the absence of capsule support. Ophthalmology. $2007 \mathrm{Jul}$; 114(7):1311-8

20 Solomon K, Gussler JR, Gussler C, Van Meter WS. Incidence and management of complications of transsclerally sutured posterior chamber lenses. J Cataract Refract Surg. 1993 Jul;19(4):488-93.

21 Vote BJ, Tranos P, Bunce C, Charteris DG, Da Cruz L. Long-term outcome of combined pars plana vitrectomy and scleral fixated sutured posterior chamber intraocular lens implantation. Am J Ophthalmol. 2006 Feb;141(2):30812.

22 Gabor SG, Pavlidis MM. Sutureless intrascleral posterior chamber intraocular lens fixation. J Cataract Refract Surg. 2007 Nov; 33(11):1851-4

23 Maggi R, Maggi C. Sutureless scleral fixation of intraocular lenses. J Cataract Refract Surg. 1997 Nov;23(9):1289-94. 
24 Yaguchi S, Yaguchi S, Asano Y, Kozawa T, Miyawaki T, Negishi K, et al. Repositioning and scleral fixation of subluxated lenses using a T-shaped capsule stabilization hook. J Cataract Refract Surg. 2011 Aug;37(8):1386-93.

25 Yamane S, Sato S, Maruyama-Inoue M, Kadonosono K. Flanged Intrascleral Intraocular Lens Fixation with Double-Needle Technique. Ophthalmology. 2017 Aug; 124(8): 1136-42.

26 Hennig A, Evans JR, Pradhan D, Johnson GJ, Pokhrel RP, Gregson RM, et al. Randomised controlled trial of anterior-chamber intraocular lenses. Lancet. 1997 Apr;349(9059):112933.

27 Dick HB, Augustin AJ. Lens implant selection with absence of capsular support. Curr Opin Ophthalmol. 2001 Feb;12(1):47-57.

28 Nehme J, Sahyoun M, Saad M, Slim E, Farhat R, Azar G, et al. Secondary intraocular lens implantation with absence of capsular support: scleral versus iris fixation. J Fr Ophtalmol. 2018 Sep;41(7):630-6.

29 Smiddy WE, Flynn HW Jr. Management of dislocated posterior chamber intraocular lenses. Ophthalmology. 1991 Jun;98(6):88994.

30 Beiko G, Steinert R. Modification of externalized haptic support of glued intraocular lens technique. J Cataract Refract Surg. 2013 Mar; 39(3):323-5.

31 Rodríguez-Agirretxe I, Acera-Osa A, UbedaErviti M. Needle-guided intrascleral fixation of posterior chamber intraocular lens for aphakia correction. J Cataract Refract Surg. 2009 Dec;35(12):2051-3.

32 Yamane S. "Transconjunctival Intrascleral IOL Fixation with Double-Needle Technique," film presented at the ASCRS Sympo- sium on Cataract, IOL and Refractive Surgery New Orleans, Louisiana, USA, May 2016 [Accessed September 6, 2019]. Available from: http://ascrs2016.conferencefilms.com/ atables.wcs? entryidZ0082\&bpZ1.

33 Yamane S, Inoue M, Arakawa A, Kadonosono K. Sutureless 27-gauge needle-guided intrascleral intraocular lens implantation with lamellar scleral dissection. Ophthalmology. 2014 Jan;121(1):61-6.

34 Faria MY, Ferreira NP, Pinto JM, Sousa DC, Leal I, Neto E, et al. Retropupillary iris claw intraocular lens implantation in aphakia for dislocated intraocular lens. Int Med Case Rep J. 2016 Aug;9:261-5.

35 Hernández Martínez A, Almeida González CV. Iris-claw intraocular lens implantation: efficiency and safety according to technique. J Cataract Refract Surg. 2018 Oct;44(10):118691.

36 Price MO, Price FW Jr, Werner L, Berlie C, Mamalis N. Late dislocation of scleral-sutured posterior chamber intraocular lenses. J Cataract Refract Surg. 2005 Jul;31(7):1320-6.

37 Khan MA, Gupta OP, Smith RG, Ayres BD, Raber IM, Bailey RS, et al. Scleral fixation of intraocular lenses using Gore-Tex suture: clinical outcomes and safety profile. Br J Ophthalmol. 2016 May; 100(5):638-43.

38 Chantarasorn Y, Techalertsuwan S, Siripanthong P, Tamerug A. Reinforced scleral fixation of foldable intraocular lens by double sutures: comparison with intrascleral intraocular lens fixation. Jpn J Ophthalmol. 2018 May; 62(3):365-72.

39 Mizuno Y, Sugimoto Y. A comparative study of transscleral suture-fixated and scleral-fixated intraocular lens implantation. Int Ophthalmol. 2019 Apr;39(4):839-45.
40 Koch DD, Jenkins RB, Weikert MP, Yeu E, Wang L. Correcting astigmatism with toric intraocular lenses: effect of posterior corneal astigmatism. J Cataract Refract Surg. 2013 Dec;39(12):1803-9.

41 Mojzis P, Piñero DP, Ctvrteckova V, Rydlova I. Analysis of internal astigmatism and higher order aberrations in eyes implanted with a new diffractive multifocal toric intraocular lens. Graefes Arch Clin Exp Ophthalmol. 2013 Jan;251(1):341-8.

42 McKee Y, Price FW Jr, Feng MT, Price MO. Implementation of the posterior chamber intraocular lens intrascleral haptic fixation technique (glued intraocular lens) in a United States practice: outcomes and insights. J Cataract Refract Surg. 2014 Dec;40(12): 2099-105.

43 Sindal MD, Nakhwa CP, Sengupta S. Comparison of sutured versus sutureless scleralfixated intraocular lenses. J Cataract Refract Surg. 2016 Jan;42(1):27-34.

44 Agarwal A, Kumar DA, Jacob S, Baid C, Agarwal A, Srinivasan S. Fibrin glue-assisted sutureless posterior chamber intraocular lens implantation in eyes with deficient posterior capsules. J Cataract Refract Surg. 2008 Sep; 34(9):1433-8.

45 Agarwal A, Jacob S, Kumar DA, Agarwal A, Narasimhan S, Agarwal A. Handshake technique for glued intrascleral haptic fixation of a posterior chamber intraocular lens. J Cataract Refract Surg. 2013 Mar;39(3):317-22.

46 Oh SY, Lee SJ, Park JM. Comparision of surgical outcomes of intraocular lens refixation and intraocular lens exchange with perfluorocarbon liquid and fibrin glue-assisted sutureless scleral fixation. Eye (Lond). 2015 Jun; 29(6):757-63. 